\title{
Occurrence of Biologically Inactive Corrinoid Compounds in Canned Edible Apple Snails (Escargots)
}

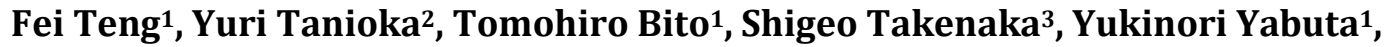 \\ Fumio Watanabe ${ }^{1^{*}}$ \\ ${ }^{1}$ Division of Applied Bioresources Chemistry, United Graduate School of Agricultural Sciences, Tottori \\ University, Tottori, Japan \\ ${ }^{2}$ Department of Nutrition, Junior College of Tokyo University of Agriculture, Setagayaku, Japan \\ ${ }^{3}$ Department of Veterinary Science, Graduate School of Life and Environmental Sciences, Osaka Prefecture \\ University, Osaka, Japan \\ Email: ${ }^{*}$ watanabe@muses.tottori-u.ac.jp
}

Received 9 July 2015; accepted 4 September 2015; published 7 September 2015

Copyright (C) 2015 by authors and Scientific Research Publishing Inc.

This work is licensed under the Creative Commons Attribution International License (CC BY).

http://creativecommons.org/licenses/by/4.0/

(c) (i) Open Access

\section{Abstract}

In this study, we characterized and quantified vitamin $B_{12}$ in canned apple snails, escargots, (boiled plain) using a microbiological assay based on Lactobacillus delbrueckii ATCC 7830. Vitamin $B_{12}$ contents of canned escargots (boiled plain) were varied from approximately $0.8 \mu \mathrm{g} / 100 \mathrm{~g}$ weight to approximately $5.5 \mu \mathrm{g} / 100 \mathrm{~g}$ weight (mean values, $2.2 \mu \mathrm{g} / 100 \mathrm{~g}$ weight). We identified vitamin $B_{12}$ compounds from escargots using liquid chromatography-electrospray ionization/tandem mass spectrometry. We found that escargots contained true vitamin $B_{12}$ and two inactive corrinoids, which were identified as factor IIIm (or methoxymensimidazolyl cyanocobamide), and factor S (or 2-methylmercaptoadenyl cyanocobamide). These results indicate that canned escargots (boiled plain) are not good sources of vitamin $B_{12}$ for humans.

\section{Keywords}

Apple Snails, Escargots, Canned Products, Factor S, Factor IIIm, Vitamin B $_{12}$

\section{Introduction}

Various species of edible land snails are consumed as apple snails (or escargots) worldwide. Escargots are high-

"Corresponding author.

How to cite this paper: Teng, F., Tanioka, Y., Bito, T., Takenaka, S., Yabuta, Y. and Watanabe, F. (2015) Occurrence of Biologically Inactive Corrinoid Compounds in Canned Edible Apple Snails (Escargots). Food and Nutrition Sciences, 6, $1071-1077$. http://dx.doi.org/10.4236/fns.2015.612111 
ly appreciated in France, Italy, Germany, and Austria. “Snails in Garlic-Herb Butter” is a standard menu item in restaurants and bistros [1]. Nowadays, they are grown and provided by snail forming. However, import of any living snails is restricted in Japan and other countries because snail pests attack crops such as leafy vegetables and fruits. Therefore, snails are usually imported as canned products [1].

Vitamin $B_{12}$ is synthesized only by certain bacteria and concentrated mainly in the bodies of higher predatory animals in the natural food chain. The usual dietary sources of vitamin $\mathrm{B}_{12}$ are animal food products (i.e., meat, milk, egg, fish, and shellfish) [2]. Shellfish that siphon large quantities of vitamin $\mathrm{B}_{12}$-synthesizing bacteria from seawater and freshwater is excellent sources of vitamin $B_{12}$ [2] [3]. However, these vitamin $B_{12}$-synthesizing bacteria can also synthesize other corrinoids with a different base moiety in the lower ligand of the molecule [4]. An edible sea snail, whelks Buccinum middendorffi, contained high amount of vitamin $\mathrm{B}_{12}$ contents (10.5 - 21.4 $\mu \mathrm{g} / 100 \mathrm{~g}$ wet weight), whereas abalone Haliotis diversicolor aquatilis had extremely low vitamin $\mathrm{B}_{12}$ contents $\left(0.3 \mu \mathrm{g} / 100 \mathrm{~g}\right.$ wet weight). In abalone, vitamin $\mathrm{B}_{12}$ and pseudovitamin $\mathrm{B}_{12}$ (an inactive corrinoid) were observed to be major and minor corrinoid compounds, respectively [5]. However, little information is available on the vitamin $\mathrm{B}_{12}$ contents of apple snails (or escargots) and on whether these contain vitamin $\mathrm{B}_{12}$ or pseudovitamin $\mathrm{B}_{12}$, which is biologically inactive in humans.

Here, we describe determination of the vitamin $\mathrm{B}_{12}$ contents of canned escargots (boiled plain) and characterization of their vitamin $\mathrm{B}_{12}$ compounds to evaluate whether they are good sources of vitamin $\mathrm{B}_{12}$.

\section{Materials and Methods}

\subsection{Materials}

Vitamin $B_{12}$ was obtained from Sigma (St Louis, Missouri, USA). A vitamin $B_{12}$ assay medium based on Lactobacillus delbrueckii subspecies lactis (formerly L. leichmannii) ATCC 7830 was obtained from Nissui (Tokyo, Japan). Silica gel 60 thin layer chromatography (TLC) aluminum sheets were obtained from Merck (Darmstadt, Germany). Canned escargots (boiled plain) were purchased from local markets in Japan.

\subsection{Extraction and Assay of Vitamin $B_{12}$ in Canned Escargot}

After broth of canned escargots (boiled plain) was removed, all solid content (escargot whole body) was homogenized using a mixer (TML160; Tescom \& Co., Ltd., Tokyo, Japan). An aliquot (2.0 g) of the homogenate was used as the sample. The vitamin $\mathrm{B}_{12}$ compounds were extracted from the sample by boiling at $\mathrm{pH} 4.5$ and then assayed using a microbiological method based on L. delbrueckii ATCC 7830, according to a previously described method [4]. L. delbrueckii ATCC 7830 can utilize deoxyribosides and deoxyribonucleotides (known to be an alkali-resistant factor) as well as vitamin $\mathrm{B}_{12}$. Thus, the correct vitamin $\mathrm{B}_{12}$ values were calculated by subtracting the values for the alkali-resistant factor from the total vitamin $\mathrm{B}_{12}$ values.

\subsection{TLC-Bioautography Assay Using Vitamin $B_{12}$-Dependent Escheríchia coli 215}

A bioautography assay to detect corrinoid compounds was performed as previously described [6]. The vitamin $\mathrm{B}_{12}$ extract $(20 \mathrm{~mL})$ prepared as described above was partially purified and concentrated using a Sep-Pak Plus ${ }^{\circledR} \mathrm{C} 18$ cartridge (Waters Corp., Milford, MA) that was washed with $5 \mathrm{~mL}$ of $75 \%$ (v/v) ethanol and equilibrated with $5 \mathrm{~mL}$ of distilled water. The C18 cartridge was washed with $5 \mathrm{~mL}$ of distilled water and vitamin $\mathrm{B}_{12}$ compounds were eluted using $2 \mathrm{~mL}$ of $75 \%(\mathrm{v} / \mathrm{v})$ ethanol. The eluate was evaporated in a centrifugal concentrator (Integrated Speed Vac ${ }^{\circledR}$ System ISS110; Savant Instruments Inc., NY, USA), and the residual fraction was dissolved in $1.0 \mathrm{~mL}$ of distilled water. Concentrated extracts $(1 \mu \mathrm{L})$ and vitamin $\mathrm{B}_{12}$ and pseudovitamin $\mathrm{B}_{12}$ (each $0.1 \mathrm{mg} / \mathrm{L}$ ) were spotted onto the silica gel 60 TLC plates and developed in the dark using 2-propanol/ $\mathrm{NH}_{4} \mathrm{OH}(28 \%) /$ water $(7: 1: 2 \mathrm{v} / \mathrm{v})$ at room temperature $\left(25^{\circ} \mathrm{C}\right)$. The TLC plate was dried and overlaid with agar-containing basal medium and precultured $E$. coli 215 , followed by incubation at $30^{\circ} \mathrm{C}$ for $20 \mathrm{~h}$. The gel plate was subsequently sprayed with methanol solution containing 2,3,5-triphenyltetrazolium salt, and vitamin $\mathrm{B}_{12}$ compounds were visualized as red, which indicated $E$. coli growth.

\subsection{Identification of Vitamin $\mathrm{B}_{12}$ Compounds by LC/ESI-MS/MS}

Each vitamin $\mathrm{B}_{12}$ extract $(40 \mathrm{~mL})$ was partially purified and concentrated using a Sep-Pak ${ }^{\circledR}$ Plus C18 cartridge 
(Waters Corp.) as described above. The eluate was evaporated to dryness under reduced pressure and the residual fraction was dissolved in $3 \mathrm{~mL}$ distilled water and centrifuged at 10,000 $\times \mathrm{g}$ for 10 min to remove insoluble material. The supernatant fraction was loaded onto an immunoaffinity column [EASI-EXTRACT ${ }^{\circledR} \mathrm{B}_{12}$ Immunoaffinity Column (P80) R-Biopharm AG, Darmstadt, Germany], and vitamin $\mathrm{B}_{12}$ compounds were purified according to the manufacturer's protocol. The vitamin $B_{12}$ compounds were purified by passage through the immunoaffinity column, dissolved in $0.1 \%(\mathrm{v} / \mathrm{v})$ acetic acid, and filtered through a Nanosep MF centrifuge device $(0.4 \mu \mathrm{m}$; Pall Corp., Tokyo, Japan) to remove small particles. An aliquot $(2 \mu \mathrm{L})$ of the filtrate was analyzed using a LC/MS IT-TOF (ion trap-time-of-flight) system coupled to an Ultra-Fast LC system (Shimadzu, Kyoto, Japan). Each purified corrinoid was injected into an Inert-Sustain column $(3 \mu \mathrm{m}, 2.0 \times 100 \mathrm{~mm}$; GL Science, Tokyo, Japan) and equilibrated with $100 \%$ solvent A [0.1\% (v/v) acetic acid] and $0 \%$ solvent B (100\% methanol) at $40^{\circ} \mathrm{C}$. Corrinoids were eluted using a linear gradient of methanol (15\% solvent B for $0-5$ min, $15 \%-90 \%$ solvent B for 5 - $11 \mathrm{~min}$, and 90\% - 15\% solvent B for 11 - $15 \mathrm{~min}$ ). The flow rate was $0.2 \mathrm{~mL} / \mathrm{min}$. ESI conditions were determined by injecting the corrinoids into the MS detector, thereby identifying the optimum parameters for detecting parent and daughter ions of vitamin $B_{12}$ compounds. The ESI-MS system was operated in the positive ion mode, and argon was used as the collision gas. Vitamin $B_{12}(\mathrm{~m} / \mathrm{z} 678.2914)$, factor IIIm or methoxymensimidazolyl cyanocobamide $(\mathrm{m} / \mathrm{z}$ 679.7834), and factor $\mathrm{S}$ or 2-methylmercaptoadenyl cyanocobamide $\left(\mathrm{m} / \mathrm{z}\right.$ 695.7657) and as $[\mathrm{M}+2 \mathrm{H}]^{2+}$ were confirmed by comparing the observed molecular ions and retention times.

\section{Results and Discussion}

\subsection{Vitamin $B_{12}$ Contents of Canned Escargots (Boiled Plain)}

We analyzed the vitamin $\mathrm{B}_{12}$ contents of canned escargots (boiled plain) that are available in Japan using the $L$. delbrueckii ATCC 7830 microbiological assay method (Table 1). Vitamin $\mathrm{B}_{12}$ contents of canned escargots (boiled plain) were varied from approximately $0.8 \mu \mathrm{g} / 100 \mathrm{~g}$ weight to approximately $5.5 \mu \mathrm{g} / 100 \mathrm{~g}$ weight. Mean values $(2.2 \mu \mathrm{g} / 100 \mathrm{~g}$ weight $)$ were approximately 3.6 -times greater than the value $(0.6 \mu \mathrm{g} / 100 \mathrm{~g}$ weight $)$ of the Japanese food composition database [7], but is very lower than values (17.4 - $39.4 \mu \mathrm{g} / 100 \mathrm{~g}$ weight) of canned clams (boiled plain) [8].

\subsection{Identification of Corrinoid Compounds from Canned Escargots (Boiled Plain) Using the E. coli 215 Bioautography}

The corrinoids observed in all escargot samples were analyzed using an E. coli 215 bioautogram after separation by silica gel 60 TLC. The corrinoids observed in all escargot samples produced clear spots which had the identical Rf value of authentic vitamin $B_{12}$, although sample A and B showed another sport, which was not identical to that of pseudovitamin $\mathrm{B}_{12}$ (Figure 1).

\subsection{LC/ESI-MS/MS Analysis}

To evaluate escargot vitamin $B_{12}$ compounds, each vitamin $B_{12}$ extract was purified using a vitamin $B_{12}$ immunoaffinity column and analyzed by LC/ESI-MS/MS. Authentic vitamin $B_{12}$ was eluted as peak with a retention

Table 1. Vitamin $\mathrm{B}_{12}$ contents of various canned escargots (boiled plain).

\begin{tabular}{cccc}
\hline & \multicolumn{2}{c}{ Amount of vitamin $\mathrm{B}_{12}$ content } & Production area \\
\cline { 2 - 3 } & $(\mu \mathrm{g} / 100 \mathrm{~g}$ wet weight $)$ & $(\mu \mathrm{g} /$ whole body $)$ & Indonesia \\
Sample A $(\mathrm{n}=3)$ & $5.5 \pm 1.0$ & $0.4 \pm 0.1$ & Indonesia \\
Sample B $(\mathrm{n}=3)$ & $1.8 \pm 0.5$ & $0.1 \pm 0.0$ & Indonesia \\
Sample C $(\mathrm{n}=3)$ & $0.8 \pm 0.4$ & $0.1 \pm 0.0$ & France \\
Sample D $(\mathrm{n}=3)$ & $1.7 \pm 0.4$ & $0.1 \pm 0.0$ & France \\
Sample E $(\mathrm{n}=3)$ & $1.4 \pm 0.4$ & $0.1 \pm 0.0$ & $0.2 \pm 0.1$ \\
Mean \pm SD & $2.2 \pm 1.9$ &
\end{tabular}

Total vitamin $\mathrm{B}_{12}$ compounds were extracted from an aliquot ( $2.0 \mathrm{~g}$ ) of each sample homogenate by boiling at $\mathrm{pH} 4.5$ in the presence of $4.0 \times 10^{-4} \% \mathrm{KCN}$ and assayed using the Lactobacillus delbrueckii ATCC 7830 microbiological assay. The vitamin $\mathrm{B}_{12}$ assay was performed in triplicate. 
time of 7.50 min (Figure 2(a)). Mass spectrum of authentic $\mathrm{B}_{12}$ indicated that a doubly charged ion with an $\mathrm{m} / \mathrm{z}$ of $678.2883[\mathrm{M}+2 \mathrm{H}]^{2+}$ was prominent (Figure 2(b)). The exact mass calculated from its formula $\left(\mathrm{C}_{63} \mathrm{H}_{88} \mathrm{CoN}_{14} \mathrm{O}_{14} \mathrm{P}\right.$ ) was 1354.5674, and the isotope distribution data showed that vitamin $\mathrm{B}_{12}$ was the major doubly charged ion under the LC/ESI-MS conditions used in our assay. The MS/MS spectrum of authentic vitamin $B_{12}$ indicated that the dominant ion at $\mathrm{m} / \mathrm{z} 359.0984$ was attributable to the nucleotide moiety. The vitamin $\mathrm{B}_{12}$ compounds purified from escargots were eluted as three ion peaks with $\mathrm{m} / \mathrm{z}$ 679.7834, $\mathrm{m} / \mathrm{z}$ 678.2914, and $\mathrm{m} / \mathrm{z} 695.7657$ at retention times of $7.35 \mathrm{~min}, 7.50 \mathrm{~min}$, and $7.65 \mathrm{~min}$, respectively (Figure 3(a)). The mass spectrum of the ion peak
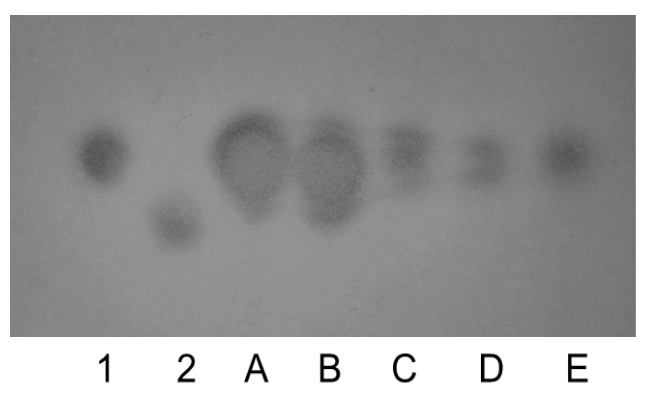

Figure 1. Escherichia coli 215 bioautogram analysis of vitamin $\mathrm{B}_{12}$ compounds detected in various canned ecargots (boiled plain). Authentic vitamin $B_{12}(1)$ and pseudovitamin $B_{12}(2)$, and extracts of canned escargots (boiled plain) sample $A$ to sample E (A - E). Data presented are typical bioautograms from three independent experiments.

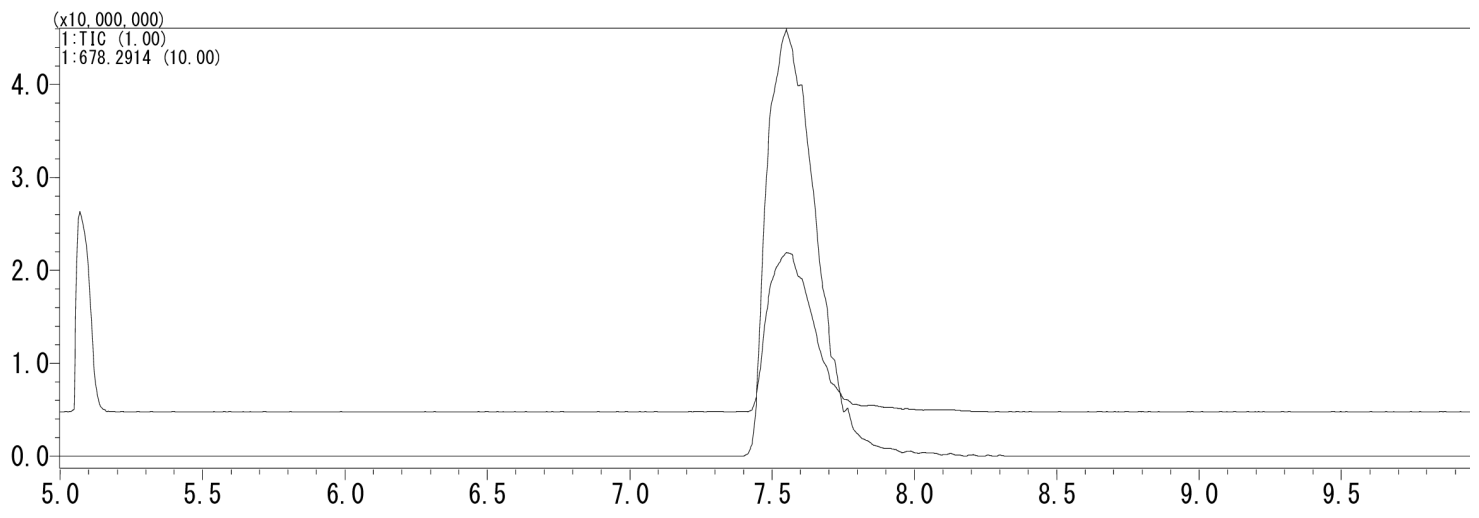

(a)

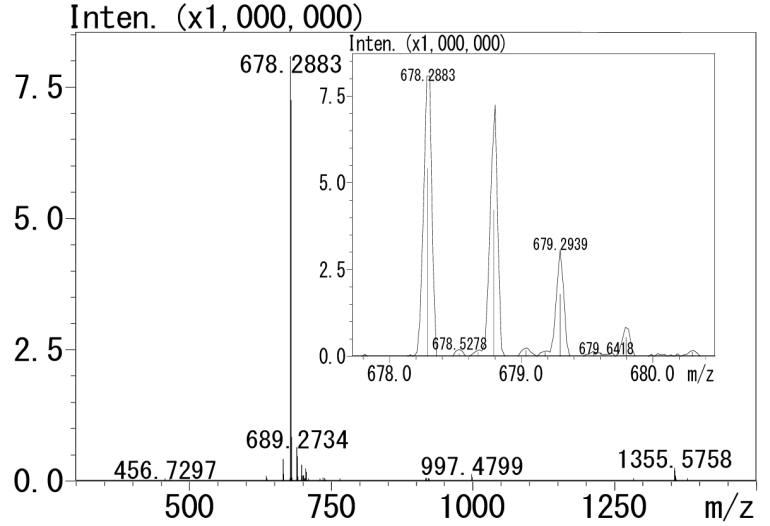

(b)

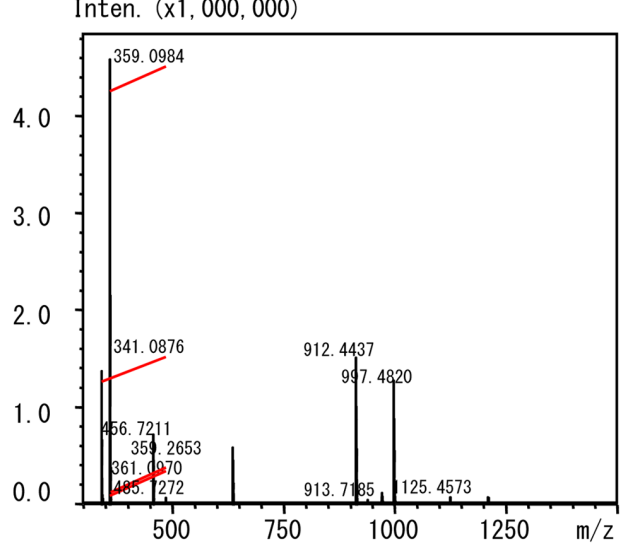

(c)

Figure 2. LC/ESI-MS/MS chromatogram of authentic vitamin $B_{12}$. Vitamin $B_{12}$ was analyzed with LCMS-IT-TOF (Shimadzu) as described in the text. The total ion chromatogram (TIC) of authentic vitamin $\mathrm{B}_{12}$ is shown in panel (a). The mass spectrum of an ion peak from vitamin $B_{12}$ is shown in panel (b). The magnified mass spectrum from $m / z 678$ to 680 in vitamin $B_{12}$ is shown as an insert. The MS/MS spectrum of the peak of vitamin $B_{12}$ is shown in panel (c). 


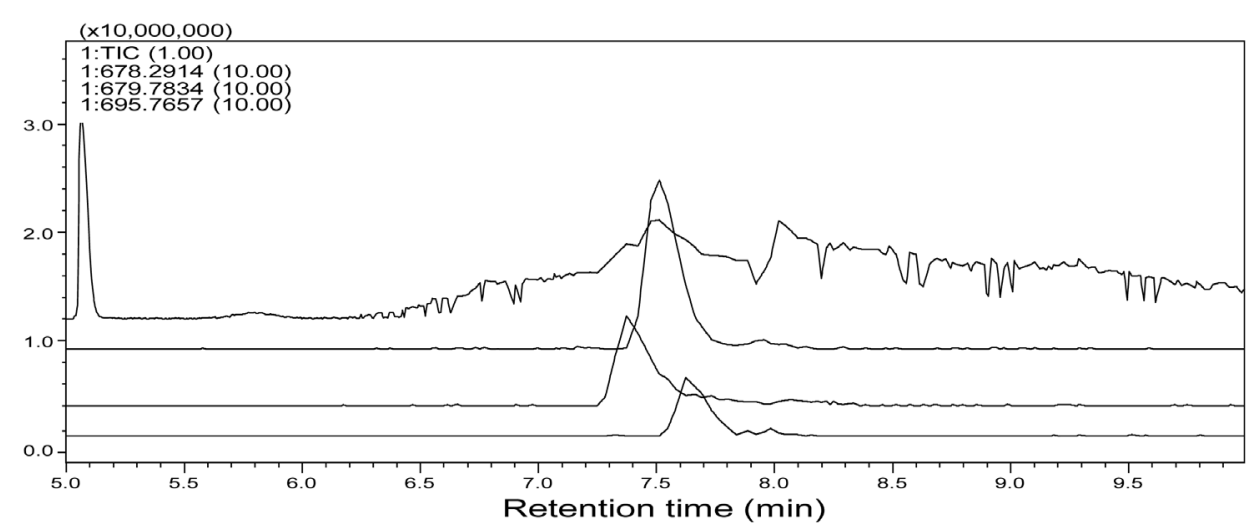

(a)
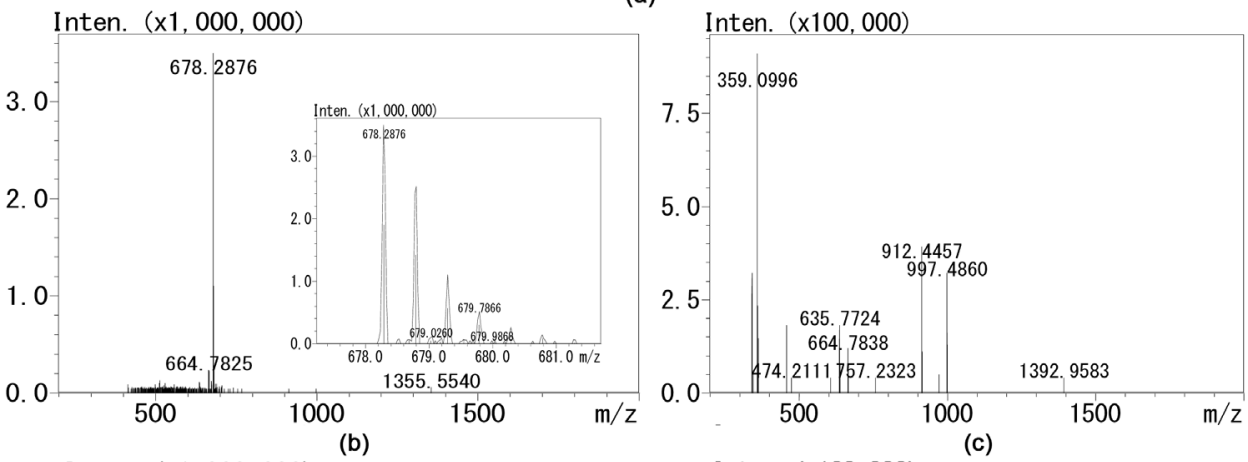

Inten. $(x 1,000,000)$

Inten. $(x 100,000)$
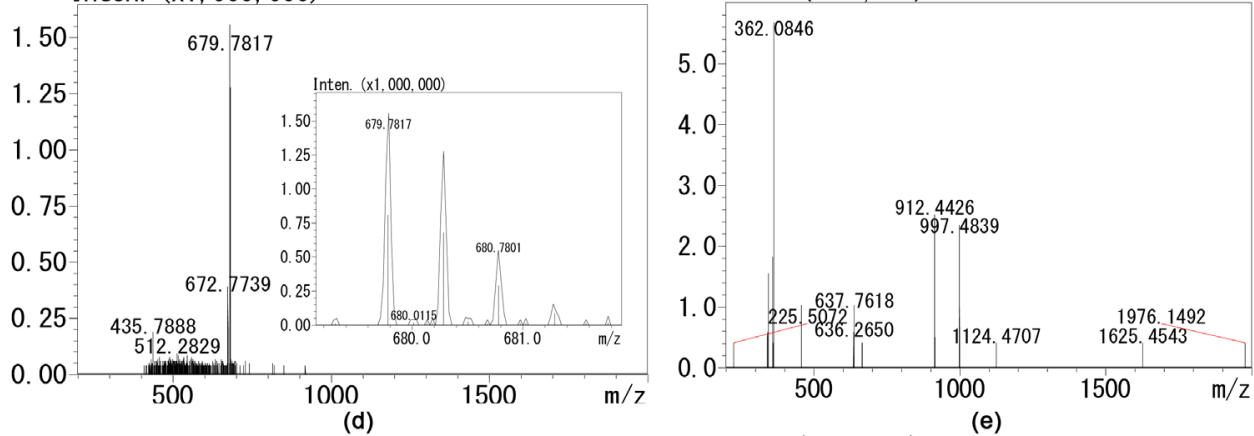

Inten. $(x 1,000,000)$

Inten. $(x 100,000)$

(e)
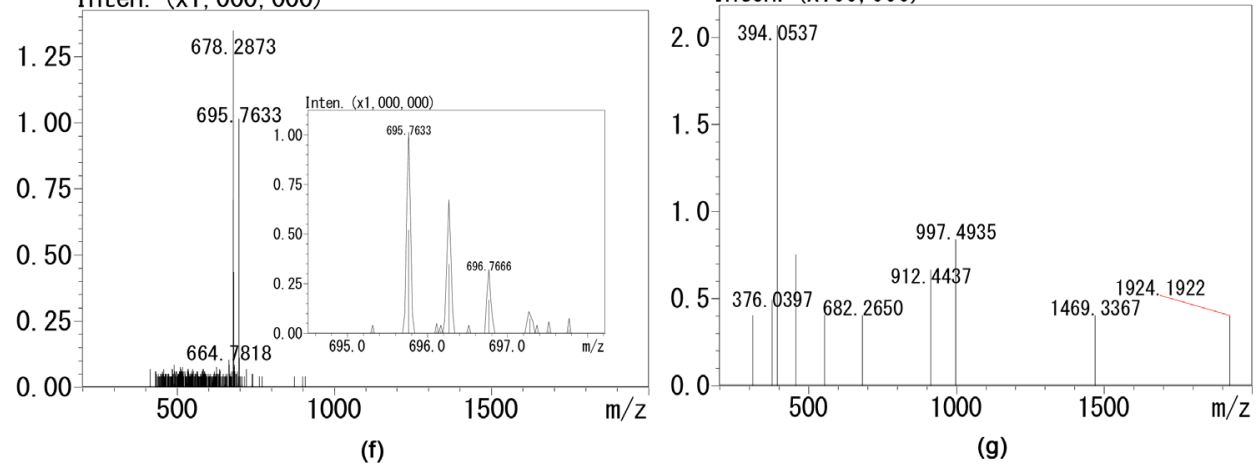

Figure 3. LC/ESI-MS/MS chromatograms of the vitamin $B_{12}$ compounds purified from the escargot sample. Total ion chromatogram (TIC) and chromatograms for $m / z 678.2914(\times 10), 679.7834(\times 10)$, and $695.7657(\times 10)$ are shown in panels (a). The mass spectra of the ion peaks of the sample A at retention times of $7.50 \mathrm{~min}, 7.35 \mathrm{~min}$ and $7.65 \mathrm{~min}$ are shown in panels (b), (d) and (f), respectively. The magnified mass spectra from 768 to 680 in (b), from 672 to 674 in (d), and from 695 to 697 in (f), are shown as respective inserts. The MS/MS spectra for the peaks of the sample A at $\mathrm{m} / \mathrm{z}$ 678.2876, 679.7817 and 695.7633 are shown in panels (c), (e) and (g), respectively. 
with $\mathrm{m} / \mathrm{z} 678.2914$ at a retention time of $7.50 \mathrm{~min}$ showed that the doubly charged ion was formed at $\mathrm{m} / \mathrm{z}$ 678.2876 (Figure 3(b)). The MS/MS spectrum of the compound was identical to that of vitamin $\mathrm{B}_{12}$ (Figure 3(c)). The mass spectra of the ion peaks with retention times of $7.35 \mathrm{~min}$ and $7.65 \mathrm{~min}$ showed that the doubly charged ions were formed at $\mathrm{m} / \mathrm{z}$ 679.7817 and 695.7633, respectively (Figure 3(d) and Figure 3(f)). The MS/MS spectra of the ion peaks of $\mathrm{m} / \mathrm{z} 679.7817$ and 695.7633 indicated that the dominant ions at $\mathrm{m} / \mathrm{z} 362.0846$ and $\mathrm{m} / \mathrm{z}$ 394.0537, respectively, were attributable to each nucleotide moiety of these compounds; these spectral data coincided with the masses of nucleotide moieties of factor IIIm or methoxybenzimidazolyl cyanocobamide $\left(\mathrm{C}_{62} \mathrm{H}_{86} \mathrm{CoN}_{14} \mathrm{O}_{15} \mathrm{P}, 1356.5467\right)$ and factor $\mathrm{S}$ or 2-methylmercaptoadenyl cyanocobamide $\left(\mathrm{C}_{60} \mathrm{H}_{85} \mathrm{CoN}_{17} \mathrm{O}_{14} \mathrm{PS}\right.$, 1389.5252) (Figure 4). The results indicated that canned escargots (boiled plain) contained vitamin $B_{12}$ and other two inactive corrinoid compounds, which are identified as factor IIIm and factor S. The similar results were obtained in the remaining samples B, C, D, and E. Relative contents of factor IIIm (34.4\% $\pm 8.6 \%)$ and factor S $(25.8 \% \pm 6.9 \%)$ against vitamin $\mathrm{B}_{12}(100 \%)$ were shown in these samples from calculating height of respective three peaks at $360 \mathrm{~nm}$.

\subsection{Escargot as a Vitamin $B_{12}$ Source}

Vitamin $\mathrm{B}_{12}$ content $(2.2 \pm 1.9 \mu \mathrm{g} / 100 \mathrm{~g}$ weight) of canned escargots (boiled plain) was very lower than values (17.4 - $39.4 \mu \mathrm{g} / 100 \mathrm{~g}$ weight) of canned clams (boiled plain). Moreover, escargots contained two inactive corrinoid compounds, which were identified factor IIIm and factor S, as well as vitamin $\mathrm{B}_{12}$. It remains unclear why these inactive corrinoids were present in escargots. Further detailed biochemical studies are required to elucidate the origins of these inactive corrinoid compounds. Escargots would be not suitable for use as a source of vitamin $\mathrm{B}_{12}$.

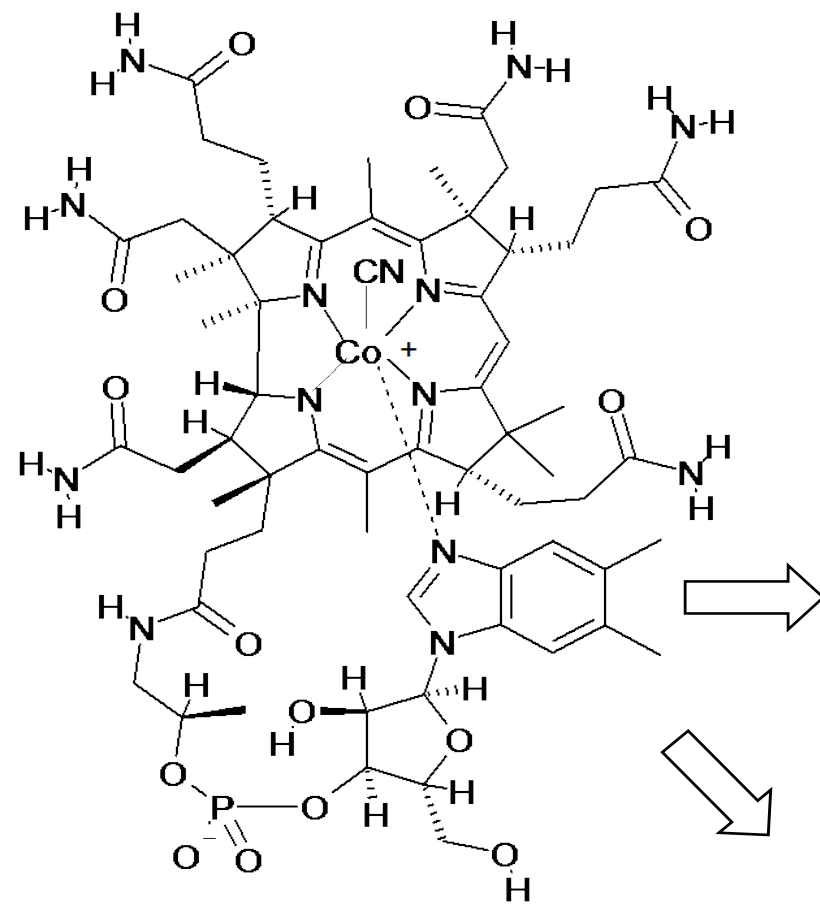

Vitamin $\mathrm{B}_{12}$<smiles>COc1ccc2c(c1)ncn2C</smiles>

Factor IIIm<smiles>CSc1nc(N)c2c(ncn2C)n1</smiles>

Factor $\mathrm{S}$

Figure 4. Structural formula of vitamin $\mathrm{B}_{12}$ and partial structures of corrinoid compounds identified from canned escargots (boiled plain). Partial structures of corrinoid compounds show only those portions of the molecule that differ from vitamin $\mathrm{B}_{12}$. 


\section{Fund}

This work was supported by JSPS KAKENHI Grant number 25450168 (FW).

\section{References}

[1] Abdulmawjood, A. and Bülte, M. (2001) Snail Species Identification by RFLP-PCR and Designing of Species-Specific Oligonucleotide Primers. Journal of Food Science, 66, 1287-1293. http://dx.doi.org/10.1111/j.1365-2621.2001.tb15203.x

[2] Watanabe, F. (2007) Vitamin $\mathrm{B}_{12}$ Sources and Bioavailability. Experimental Biology and Medicine, 232, 1266-1274. http://dx.doi.org/10.3181/0703-MR-67

[3] Herbert, V. (1996) Vitamin $B_{12}$. Present Knowledge in Nutrition. 7th Edition, International Life Sciences Institute Press, Washington DC, 191-205.

[4] Watanabe, F., Katsura, H., Takenaka, S., Fujita, T., Abe, K., Tamura, Y., Nakatsuka, T. and Nakano, Y. (1999) Pseudovitamin $\mathrm{B}_{12}$ Is the Predominant Cobamide of an Algal Health Food, Spirulina Tablets. Journal of Agricultural and Food Chemistry, 47, 4736-4741. http://dx.doi.org/10.1021/jf990541b

[5] Tanioka, Y., Takenaka, S., Furusho, T., Yabuta, Y., Nakano, Y. and Watanabe, F. (2014) Identification of Vitamin B 12 and Pseudovitamin $\mathrm{B}_{12}$ from Various Edible Shellfish Using Liquid Chromatography-Electrospray Ionization/Tandem Mass Spectrometry. Fisheries Science, 80, 1065-1071. http://dx.doi.org/10.1007/s12562-014-0787-X

[6] Tanioka, Y., Yabuta, Y., Miyamoto, E., Inui, H. and Watanabe, F. (2008) Analysis of Vitamin B $_{12}$ in Food by Silica Gel 60 TLC and Bioautography with Vitamin $\mathrm{B}_{12}$-Dependent Escherichia coli 215. Journal of Liquid Chromatography \& Related Technologies, 3, 1977-1985. http://dx.doi.org/10.1080/10826070802197453

[7] Ministry of Education, Culture, Sports, Science and Technology (2010) Report of the Subdivision of Resources. Standard Tables of Food Composition in Japan-2010. The Council for Science and Technology, Ministry of Education, Culture, Sports, Science and Technology, Tokyo, 170-173.

[8] Ueta, K., Takenaka, S., Yabuta, Y. and Watanabe, F. (2011) Broth from Canned Clams Is Suitable for Use as an Excellent Source of Free Vitamin $\mathrm{B}_{12}$. Journal of Agricultural and Food Chemistry, 59, 12054-12058. http://dx.doi.org/10.1021/jf2037104 